\title{
Development of crack on composite detection sensor using magnetic induction concept
}

\author{
N. I. Ismail, W. N. A. Rashid, N. Lokmanulhakim \\ Department of Electronic and Computer Engineering Technology, Universiti Teknikal Malaysia Melaka, Malaysia
}

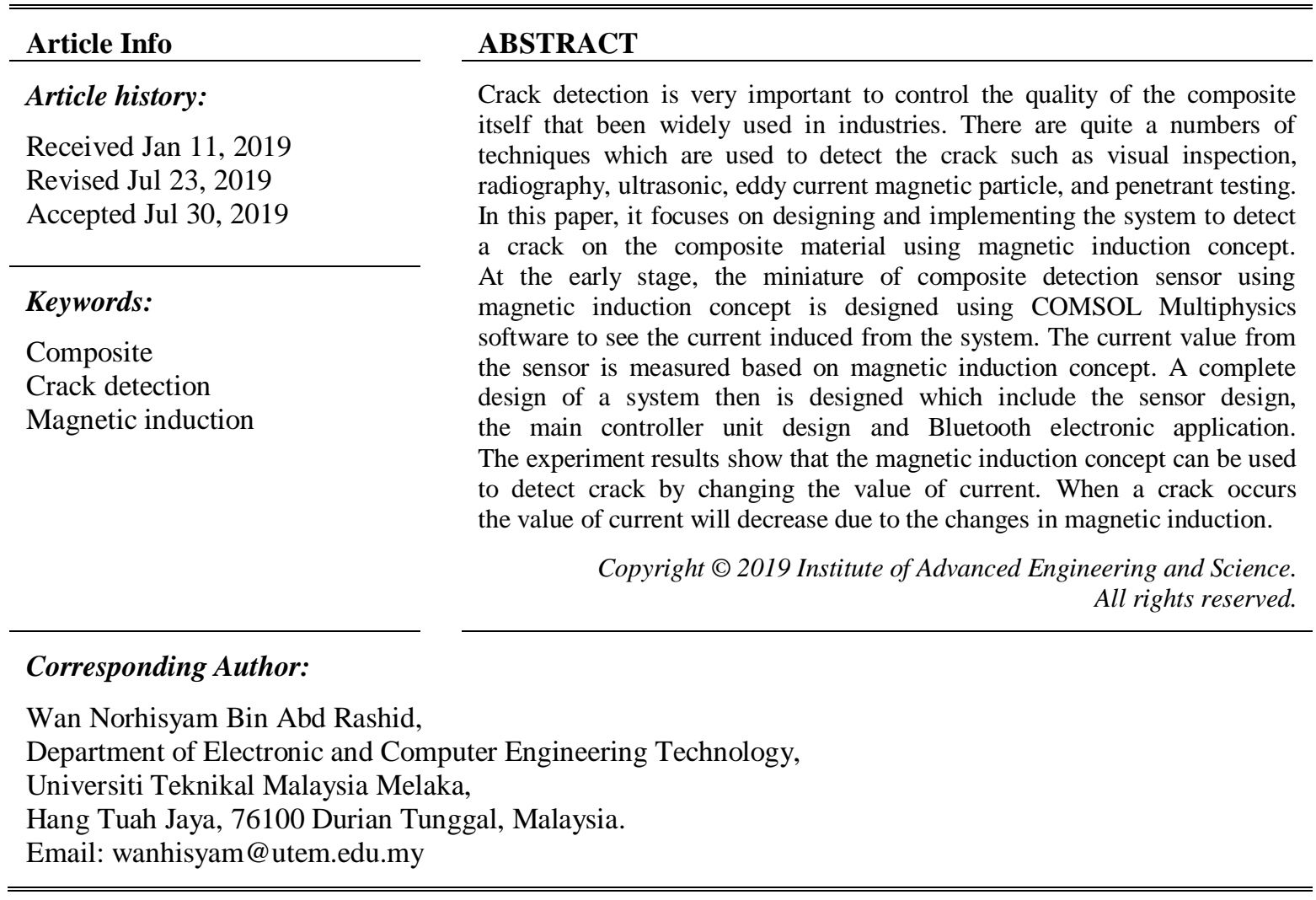

\section{INTRODUCTION}

Composites are commonly used in high-performance products, such as aerospace components or storage tanks. It's usually exposed to harsh loading condition thus, composite material will easily to forming crack and propagation. However, visible cracking is one aspect that occasionally causes problems and dangers to the community. There is numerous crack detection has been developing in the past decades. In the previous study, there was an implementation of crack by using the various method of non-destructive technique (NDT). NDT has been widely used for evaluating the condition of the composite. Visual inspection is normally used to detect surface damage by observing the transmitted or reflected light [1]. Another technique of NDT is radiography [2-4] which can detect internal and surface discontinuity. There are few publications mention that ultrasonic technique [5-7] can spot the radiographic density variation and geometrical dimension of defects and discontinuities. Another technique to detect a defect in the electrically conducting material is eddy current $[8,9]$. For magnetic particle technique [10-12] it can check magnetic materials defect on surface and sub-surface. Penetrant testing [13, 14] is the most widely applied NDT techniques because it can detect the defects open to the surface in all except for highly porous materials. All methods have their own advantages.

Instated of using the previous methods, the writer wants to purpose a new concept to detect cracks on composite using magnetic induction concept. This concept was related to electromagnetic induction and eddy current theory. The purpose to carry out this project is to show evidence that it is possible to detect a crack in composite using magnetic induction concept. 


\section{MAGNETIC INDUCTION PRINCIPLE}

Basically, the fundamental principles of magnetic induction (MI) are based on a basic mutual inductance and eddy current theories $[15,16]$ (Figure 1). Generally, the primary magnetic field is generated by passing an alternating current through one or more excitation coils. This will cause an electric field appreciable by one or more measuring coils. Thus the induced voltage can be measured from the electrical field. When the conductive material is placed within the field, it will produce an eddy current. In the same time, it also generates a magnetic field known as the secondary field. Therefore the electrical field on the measuring coil will be induced at primary and secondary fields. The induced voltages on the measuring coil will change depending on whether a conductive material is present within the field. If no material is present, the induced voltage appears entirely due to the primary field, whereas if there is material present, the induced voltage appears due to both primary and secondary fields.

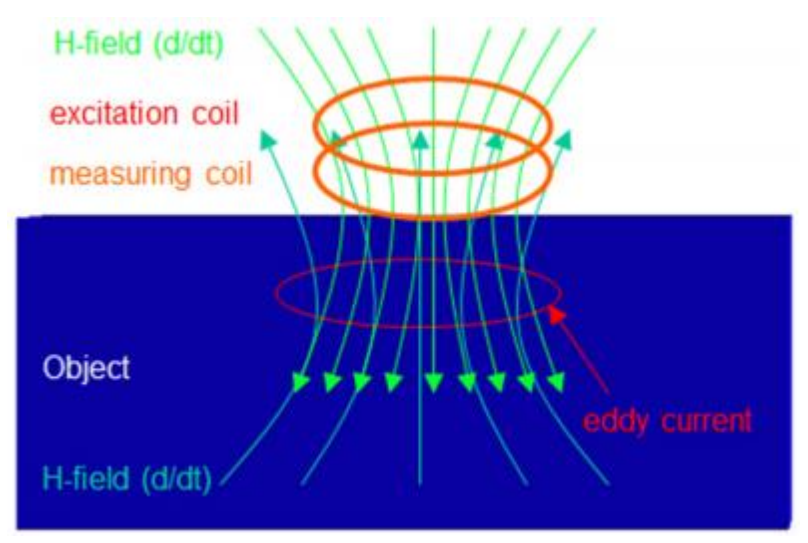

Figure 1. Fundamental principles of MI [17]

\subsection{Operation of magnetic induction sensors}

Figure 2 displays a basic MI sensor. MI sensor consist of the coil made by $\mathrm{N}$ turns with wire diameter. Then it's will wound at the average radius around the core. The core must be high-permeability but low in conductivity. The permeability will represent the amount of flux concentration in the core. Permeability is a function of the material permeability, the core geometry, and its aspect ratio [18]. A low-frequency ambient magnetic field $\mathrm{H}$ can be referred to as the MI to the rate of change of the magnetic flux is proportional to the electromotive force (emf) and coil induction.

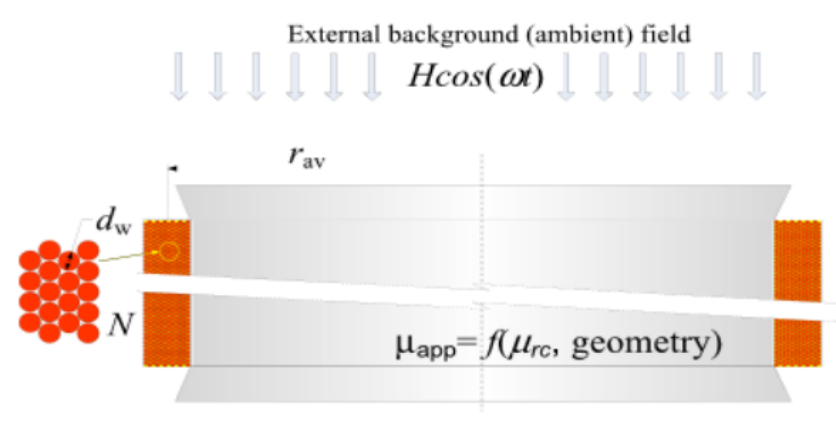

Figure 2. Cross-section of induction loop sensor made of a multiturn coil wrapped around a permeable core [19]

\subsection{Main control unit design}

The measurement circuit of this project will consist of the magnetic induction sensor, crack detection circuit, amplifying circuit, filtering circuit, and also analog to digital converter circuit (ADC). Figure 3 shows the block diagram of the magnetic induction system. At the first stage, a signal from the function generator drives $10 \mathrm{KHz}$ of a sine wave with an excitation voltage of $10.6 \mathrm{Vpp}$ to a magnetic induction sensor. Then, the sensor was connected to the crack detection circuit. After that, alternating currents flow to the detector circuit and produce the voltage corresponding to the current value produce at 
the sensor. The voltage value produced has been amplified by the amplifier circuit before the signal sends to the RC filter to filter out the unwanted signals and produce a clean DC output. The data in an analog form which has been collected from the sensor will be transferred to an analog to digital converter using Arduino module to digitally record and display the quality of composite at Bluetooth Electronic application. By using this apps user can read the value of materials before and after the sensor detect the crack.

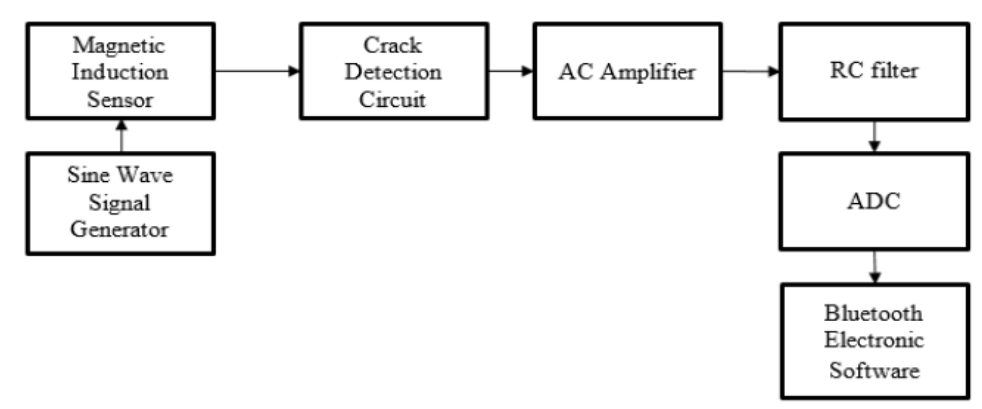

Figure 3. Block diagram of the system

\subsection{Bluetooth application}

The Bluetooth electronics application was being designed in this application. It will be interfaced with an Arduino module to record the analog inputs and calculate the voltage output produced as shown in Figure 4. From the voltage, the application will display both cracks and not crack the value of the material. For this app, it consists of three particular screens. First is the main screen which all the operation will display here. From the main screen, the user can observe the value of the materials before and after the crack. The second screen is connected to the Bluetooth screen. The purpose of this screen is to check the connectivity between the HC-05 Bluetooth module devices with the Arduino. The last screen is the editing screen which user can make any changes here. Figure 5 show the experiment set-up.

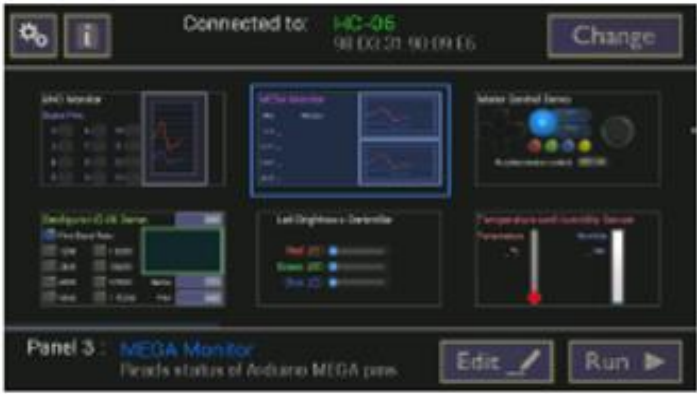

(a)

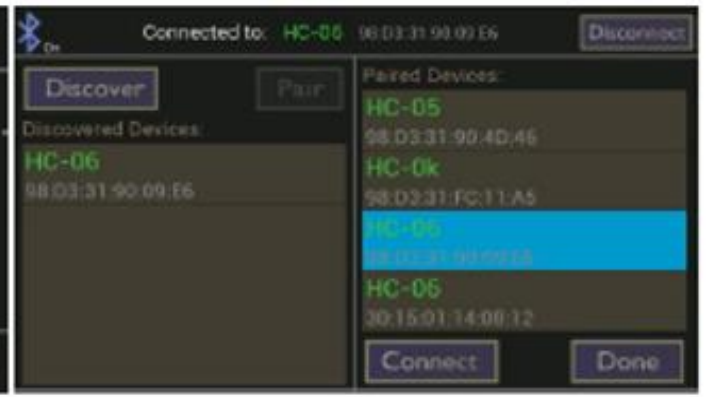

(b)

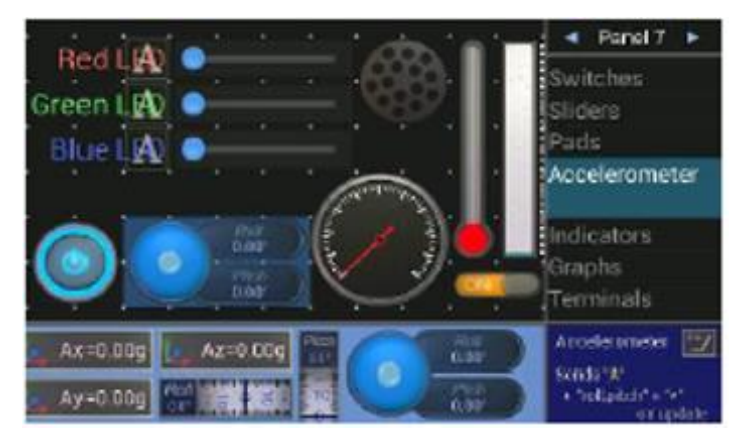

(c)

Figure 4. Bluetooth electronics application (a) Main screen;

(b) Connect to bluetooth screen; (c) Edit screen 


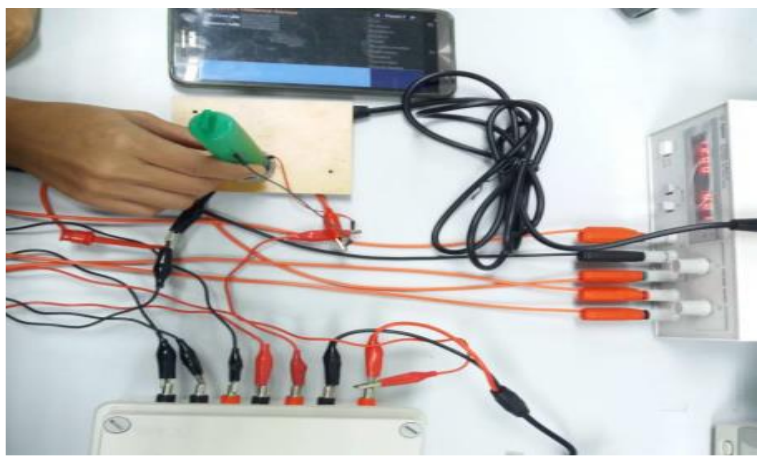

Figure 5. Experiment set-up

\section{RESULT AND DISCUSSION}

The experiment was carried out to detect a crack in composite using magnetic induction concept. At the early stages, the working principle of the sensor is studied using the COMSOL Multiphysics software. From this software, the streamline of magnetic flux density and contour of induced current density was recorded. Then, this experiment was continued with developed full experiment setup. Thus, the data of current values between cracks or without crack was taken.

\subsection{COMSOL multiphysics simulation}

For this experiment three types of material were tested; carbon steel, FR4, and iron. The distance between the sensor and material was varied for $10 \mathrm{~mm}$ and $20 \mathrm{~mm}$. The reason for varies the distance is to study the effect of distance toward the value of induced current. Other than that, the simulation also generates the streamline of magnetic flux density. In this simulation, the pattern of mesh analysis also will be done. The simulation results are shown in the Figures 6 to 8 .

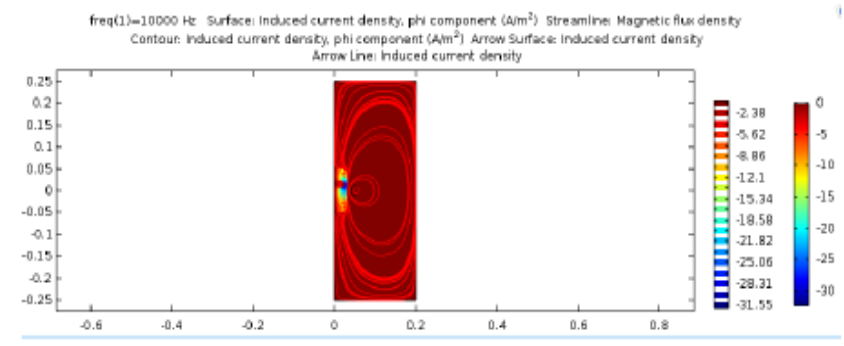

(a)

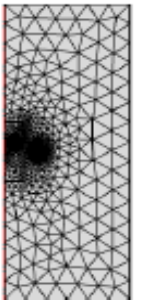

(a)

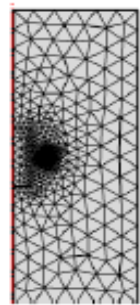

(b)

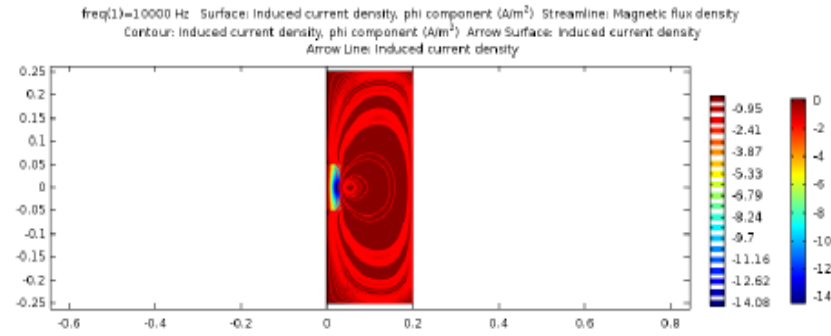

(b)

Streamline of magnetic flux density and contour of induced current density: (a) with crack; (b) without crack

Figure 6. Material: carbon steel 


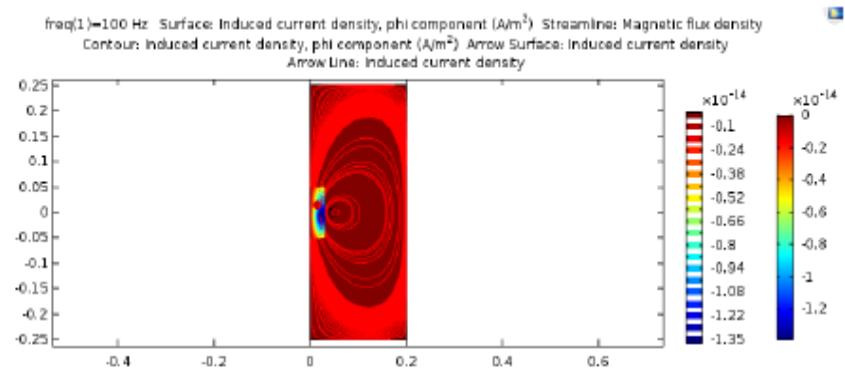

(a)

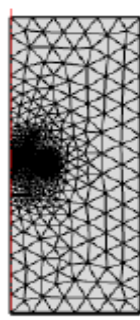

(a)

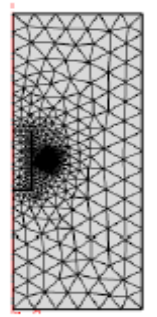

(b)

Mesh analysis: (a) with crack; (b) without crack

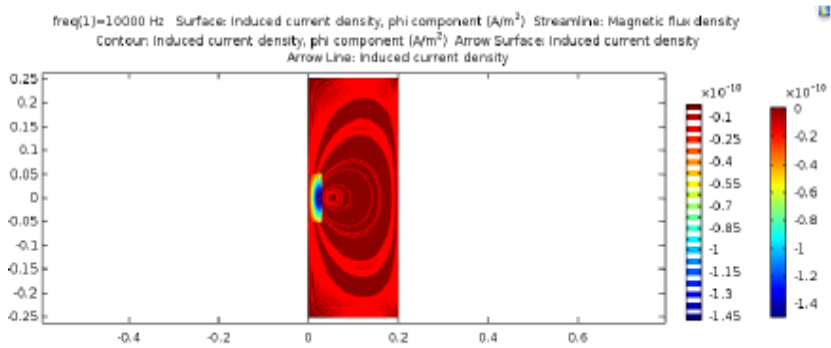

(b)

Streamline of magnetic flux density and contour of induced current density: (a) with crack; (b) without crack

Figure 7. Material: FR4

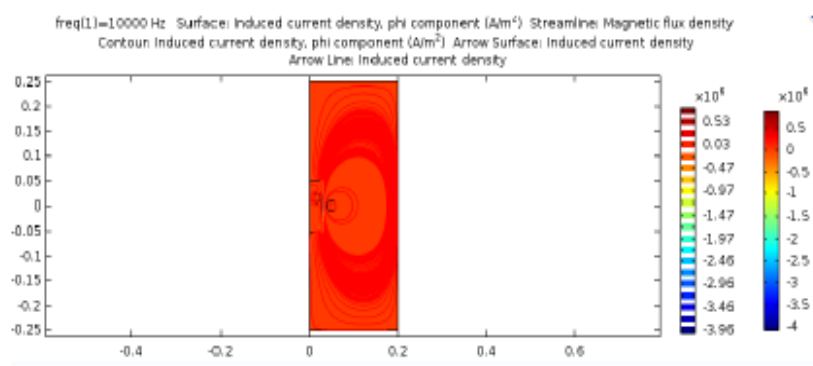

(a)

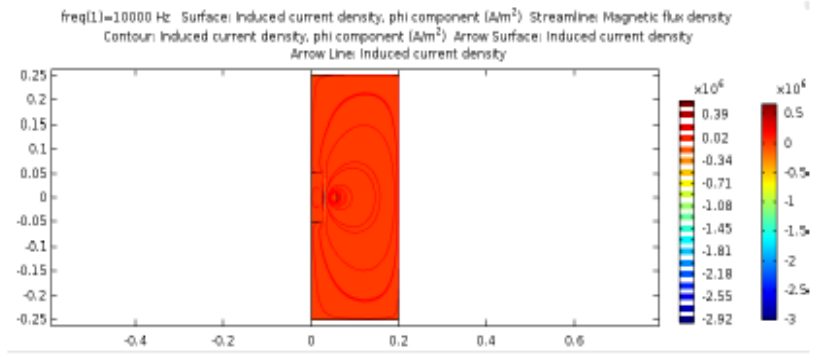

(b)

Streamline of magnetic flux density and contour of induced current density: (a) with crack; (b) without crack

Figure 8. Material: iron 
Table 1 shows the relationship between the distance and value of current for three types of difference material tested. From the observation, it can be concluded that the distance between the material and sensor will influence the current value. The current value was high at $10 \mathrm{~mm}$ compared to $20 \mathrm{~mm}$. this pattern is the same as all materials tested. Besides that, carbon steel state the highest value of current follow by FR4 and iron. When the material was crack the value of current will slightly decrease.

\begin{tabular}{cccc}
\multicolumn{3}{c}{ Table 1. The relationship between distance, types of material and current value } \\
\hline Distance $(\mathrm{mm})$ & Material & \multicolumn{2}{c}{ Current Value $(\mathrm{mA})$} \\
& & Without Crack & With Crack \\
\hline 10 & Iron & 0.637 & 0.479 \\
& FR4 & 1.171 & 0.646 \\
\multirow{2}{*}{20} & Carbon Steel & 1.421 & 0.927 \\
& Iron & 0.543 & 0.399 \\
& FR4 & 0.863 & 0.573 \\
& Carbon Steel & 1.003 & 0.874 \\
\hline
\end{tabular}

\subsection{Hardware results}

For the hardware parts basically the idea of design a sensor were made from the concept idea of design and fabrication of low-cost eddy current [20] and design and construction of railway cracks detection based on eddy current [21]. The sensor connected to the conditioning circuit and finally produce a voltage from the current values obtained. As for the sensor, the diameter and number of turns of the coil are $0.5 \mathrm{~mm}$ and 62 turns. The magnet used is supposedly ferromagnetic magnet but because of limited sources of the magnet, this project used 10 neodymium magnet and be wrapped with the copper. As can see in the Figure 9 shows the relationship between types of material and current value with and without a crack. A changing magnetic field is generated by an alternating current [22]. When the magnet and coil are located in a specimen, the first magnetic field causes eddy current. It was the same concept as magnetic induction. As the eddy current meets a crack, it will avoid it and show a higher conductivity region. Eddy current will produce its own magnetic field in the test piece. Eddy current line penetrates into the specimen and this process called magnetic induction [23]. Thus, present crack of material can be detect by monitoring changes in the eddy current flow [24]. The experiment was carried out with $10 \mathrm{KHz}$ and $10.6 \mathrm{Vpp}$ excitation voltage was injected into the magnet coil and connected to the crack detection circuit. Normally, the triode differential amplifier enlarges inverting inputs. Therefore, if there is a crack, it outputs a voltage. The full-wave rectifier modifies the direction of the voltage. It is dealt with the filter. The RC filter aims to alter the alternating current into a direct one. Once it is finished, the filtered voltage should be over zero with a small undulation [25].

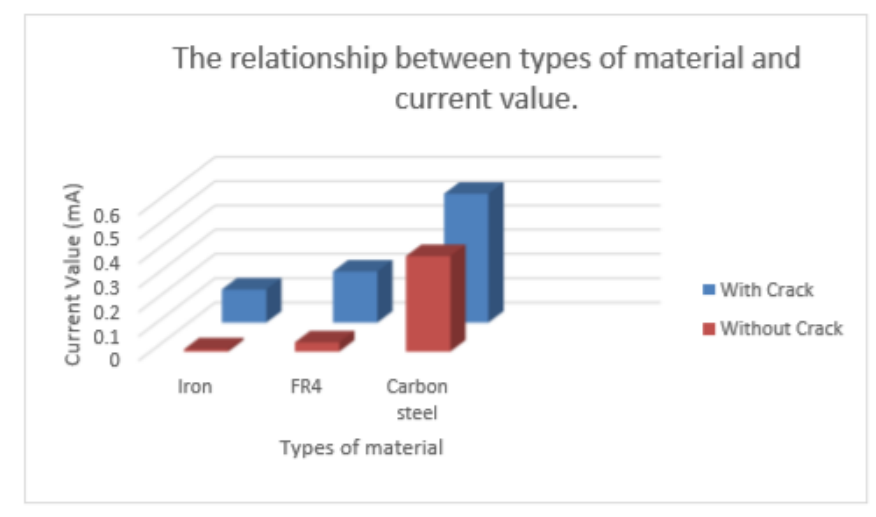

Figure 9. The relationship between the types of material and current value

The current value obtained as recorded in Table 2 shows the relationship between three of the material used in this project with the current value. The value produced was too small and sometimes it produces inconstant value and the current could not be read. It shows the decreasing value of the current when there was a crack in the specimen test. Figure 10 shows hardware setup between types of material used with the sensor (a) carbon steel; (b) FR4; (c) iron. 
Table 2. The relationship between the material and current value

\begin{tabular}{ccc}
\hline \multirow{2}{*}{ Material } & \multicolumn{2}{c}{ Current Value (mA) } \\
& Without Crack & With Crack \\
\hline Iron & 0.137 & 0.009 \\
FR4 & 0.211 & 0.038 \\
Carbon Steel & 0.531 & 1.393 \\
\hline
\end{tabular}

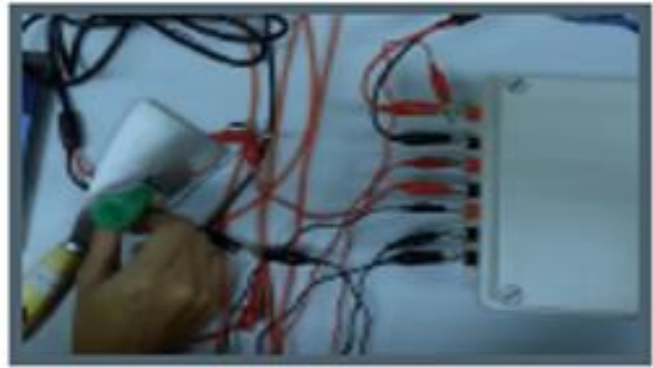

(a)

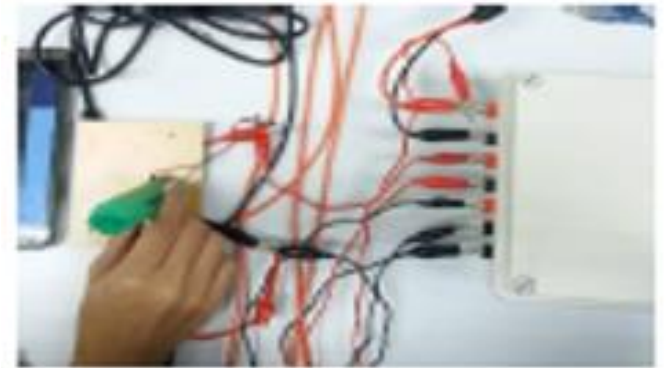

(b)

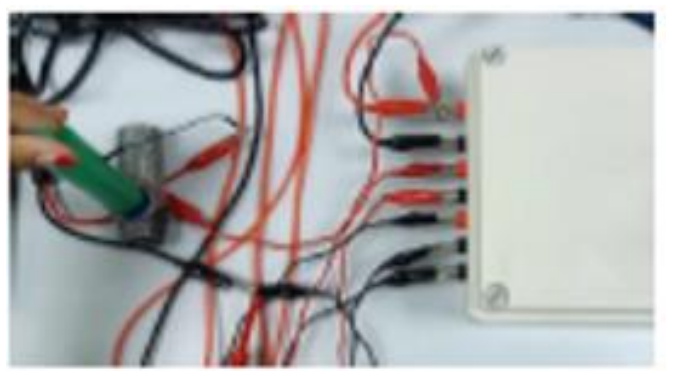

(c)

Figure 10. Hardware setup between types of material used with the sensor (a) carbon steel; (b) FR4; (c) iron

\section{CONCLUSION}

As a conclusion, the crack detection sensor using magnetic induction concept was introduced in this project to detect and distinguish between cracks and not crack in the composite material. From the COMSOL Multiphysics simulation study, the performance of a magnetic induction sensor is examined based on different types of composite material. For the development of a magnetic induction sensor system, the experiment was carried out based on the crack detection circuit connected to Arduino and Bluetooth Electronics using the HC-05 module. The qualities of the composite were analyzed and displayed via Bluetooth through the application. For a hardware implementation, this project only focused to display the quality of the composite. The current value was measured to distinguish the quality of the composite.

\section{FUTURE WORK}

Presently, the process of development of a crack on composite detection sensor using magnetic induction concept is an initial stage. There are still significant to improve the system in order to apply it in an industrial area in the future. The suggestion and recommendation for future works are mentioned: a) Development magnetic induction sensor in close area to reduce the noise of fringe effect from the environment surrounding to get the accurate value of current. b) Using a coaxial cable for a magnetic induction sensor connector to reduce the noise when the current value is measured. c) Development a single module of the PCB circuit to simplify the hardware. d) Develop a well develop main body sensor to make sure the surrounding did not disturb the magnetic field as well as the current value. e) Upgrade the system to detect the flaws or cracks of the material in term of image processing that can be monitored in the computer system. 


\section{ACKNOWLEDGMENTS}

Authors are grateful to the financial support by Research Grant of the Ministry of Higher Education (RAGS Grant: RAGS/1/2015/TK0/FTK/03/B00117) and Universiti Teknikal Malaysia Melaka. Thanks to the staff and members of UTeM who give assistance and commitment to me and guide me in various perspective throughout the project. Special thanks must be given to my friends for ideas and comment regarding my project.

\section{REFERENCES}

[1] B. Raj, et al., Practical non-destructive testing, Cambridge England: Woodhead Publishing, pp. 4-7, 2002.

[2] M. Jolly, et al., "Review of Non-destructive Testing (NDT) Techniques and their Applicability to Thick Walled Composites," Procedia CIRP, vol. 38, pp. 129, 2015.

[3] Raj B., et al., Practical Non-destructive Testing, Oxford: pub Alpha science international ltd. 3rd Ed., 2008.

[4] Harara W., "Digital Radiography in Industry," Shanghai, China: 17th World Conference on Non-Destructive Testing, Shanghai, China, 2008.

[5] Adamowski J. C., et al., "A Large Aperture Ultrasonic Receiver for Through Transmission Determination of Elastic Constants of Composite Materials," Beijing: IEEE, 2008.

[6] P. J. Shull, Nondestructive evaluation: theory, techniques, and applications, CRC press, Altoona, Pennsylvania, pp. 65-69, 2016.

[7] O. S. Zahran, et al., "Recent Developments in Ultrasonic Techniques for Rail-track Inspection," NDT 2002, Southport, the British Institute of NDT, 2002.

[8] V. M. Karbhari, "Non-destructive evaluation (NDE) of polymer matrix composites," Elsevier, pp. 35, 2013.

[9] F. Tariq, et al., "Characterization of material properties of $2 \mathrm{xxx}$ series al-alloys by non-destructive testing techniques," Journal of Nondestructive Evaluation, vol. 31, pp. 17-33, 2012.

[10] L. Zhiyong, et al., "New Magnetic Particle Cassette NDT Intelligent Detection Device," Intelligent Systems Design and Engineering Applications, 2013 Fourth International Conference on, IEEE, pp. 403-406, 2013.

[11] L. Ximeng, “Comparative Study on Nondestructive Testing Technology of Reliability," Suizhou: Proceedings of the Eighth Annual National Non destructive Testing, 2003.

[12] Y. Heng and X. Zou, "Design and Construction of Railway Cracks Detection Based on Eddy Current," Advanced Materials Research, Trans Tech Publications, vol. 986, pp. 1709-1713, 2014.

[13] J. Czuchryj and S. Sikora, "Grounds of penetration testing of industrial products," Instytut Spawalnictwa, Gliwice, pp. 5-24, 2007.

[14] P. Irek and J. Słania, "Material Factors in Relation to Development Time in Liquid-Penetrant Inspection," Material Factors. Archives of Metallurgy and Materials, vol. 61, pp. 509-514, 2016.

[15] Yu Z. Z., et al., "Imaging system based on electromagnetic tomography," Electron. Lett., vol. 29, pp. 625-6, 1993.

[16] Lyon G. M., et al., "Developments in electro-magnetic tomography instrumentation," IEE Colloquium Adv. Electr. Tomogr., vol. 12, pp. 1-4, 1996.

[17] L. Ma and M. Soleimani, "Magnetic induction tomography methods and applications: a review," Measurement Science and Technology, vol. 28, 2017.

[18] C. Coillot and P. Leroy, "Induction magnetometers principle, modeling and ways of improvement," Magnetic Sensors-Principles and Applications. Rijeka, Croatia: InTech, vol. 1, 2012.

[19] Y. Morag, et al., "Thermodynamic signal-to-noise and channel capacity limits of magnetic induction sensors and communication systems," IEEE Sensors Journal, vol. 16, pp. 1575-1585, 2016.

[20] P. Ragunathan and E. Logashanmugam, "Design and Fabrication of Low Cost Eddy Current Sensor for Position Control Applications," Indian Journal of Science and Technology, vol. 9, 2016.

[21] Y. Sheng and X. Zou, "Design and Construction of Railway Cracks Detection Based on Eddy Current," Advanced Materials Research, Trans Tech Publications, vol. 986, pp. 1709-1713, 2014.

[22] H. Y. Wei, et al., "Volumetric magnetic induction tomography," Measurement Science and Technology, vol. 23, pp. 055401, 2012.

[23] H. Hashizume, et al., "Numerical and experimental analysis of eddy current testing for a tube with cracks," IEEE Trans. Magn., vol. 28, pp. 1469-1472, 1992.

[24] J. G. Martín, et al., "Non-Destructive Techniques Based on Eddy Current Testing," Sensors, vol. 11, pp. 2525-2565, 2011.

[25] S. J. Kim, "Damage detection in composite under in-plane load using tap test," Journal of Mechanical Science and Technology, vol. 29, pp. 199-207, 2015. 


\section{BIOGRAPHIES OF AUTHORS}

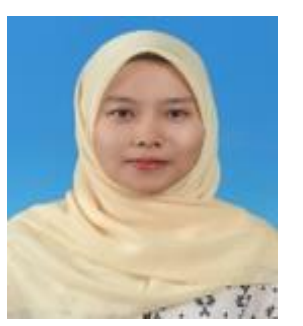

Nurfarah Izzati, student of Bachelor Degree in Electronics Engineering Technology (Telecommunication), Department of Engineering Technology at University of Technical Malaysia Melaka (UTeM).

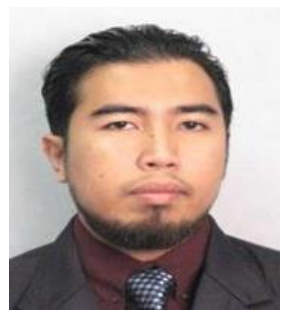

Wan Norhisyam Bin Abd Rashid received his Diploma Ing. (Fh) in Fachhochschule Reutlingen. Then he persuade his study in Master of Electrical Engineering from UTHM. Currently, he is a Lecturer at Universiti Teknikal Malaysia Melaka (UTeM) and his interest are in tomography and embedded control system.

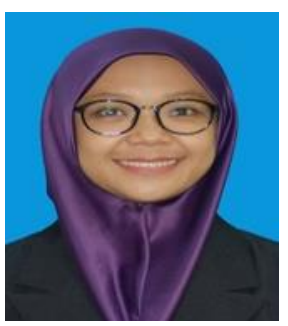

Nurhanis Binti Lokmanulhakim is a postgraduate student from Universiti Teknikal Malaysia Melaka. Before that, she graduated in Bachelor of Electronic Engineering Technology in Electronic Industries (Hons.) in Universiti Teknikal Malaysia Melaka. Previously, she has been working on a semiconductor company which is known as Plexus Manufacturing Snd Bhd as the Process Engineer. Her area of interest are power electronics, and sensors. 